\title{
Experimental Investigation on Quantitative Nanomechanical Properties of Cement Paste
}

\author{
by Wengui Li, Jianzhuang Xiao, Shiho Kawashima, Gajendra S. Shekhawat, and Surendra P. Shah
}

Nanoindentation, quantitative modulus mapping, and PeakForce quantitative nanomechanical mapping (QNM) are applied to investigate the quantitative nanomechanics of hardened cement paste at different spatial resolutions. The elastic modulus measured by static nanoindentation is slightly higher than those measured by the other methods. The average elastic modulus and probability obtained by PeakForce QNM are typically consistent with those found by modulus mapping. Both modulus mapping and PeakForce QNM can be used to discriminate different material phases in cement paste at the nanoscale. It concludes that cement paste is a granular material in which the sub-micron scale grains or basic nanoscale units pack together. Moreover, the high resolution PeakForce QNM can provide an efficient tool for identifying nanomechanical properties, particle sizes, and thickness of the interface between different nanoscale grains.

Keywords: cement paste; nanoindentation; nanomechanical properties; modulus mapping; PeakForce quantitative nanomechanical mapping (QNM).

\section{INTRODUCTION}

Exploring the properties of cement-based materials at the nanoscale has received much attention in recent years. ${ }^{1-4}$ Measurement of nanoscale mechanical properties of cementbased materials is necessary in understanding the phase characteristics, the initiation of microcracking under loading, and physical transport properties of concrete. Recently, three advanced techniques have been developed: 1) depth-sensing nanoindentation ${ }^{5-7}$; 2) quantitative modulus mapping in the form of scanning probe microscopy (SPM $)^{8-11}$; and 3) atomic force microscopy (AFM)-based PeakForce quantitative nanomechanical mapping (QNM). ${ }^{12-15}$ The capabilities of these instruments cover a wide range of contact areas and displacement resolutions from the sub-micron scale in nanoindentation down to nanoscale in PeakForce QNM.

Nanomechanical testing can be used to assess the mechanical properties of the individual constituents of heterogeneous materials and, in this way, to provide meaningful experimental data for multi-scale numerical modeling. Nanoindentation has been a popular technique used for this purpose. ${ }^{16,17}$ In nanoindentation, the in-place imaging method allows for observing the surface topography and placing the indents at the desired locations. ${ }^{18,19}$ Statistic techniques have been argued to determine the elastic modulus of different phases in cement paste. ${ }^{20-24}$ During nanoindentation testing, a diamond indenter is inserted into the surface of the sample, which would cause damage to the surface. As for the quantitative modulus mapping technique, the advantage is that the contact stiffness can be obtained continuously during scanning using a smaller contact force, which could be an ideal technique for multi-phase and composite materials. ${ }^{10,11}$ PeakForce QNM has been recognized as a useful

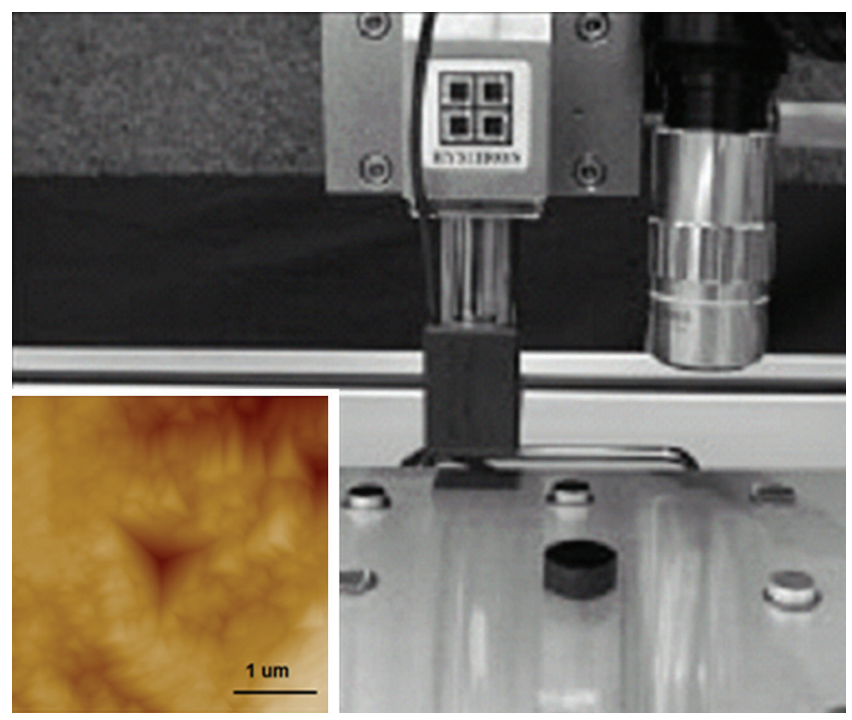

Fig. 1-Nanoindentation device.

method for the assessment of local mechanical properties of materials, which can also provide phase contrast maps for qualitative characterization of materials with a high spatial resolution. ${ }^{12,14}$

\section{RESEARCH SIGNIFICANCE}

The objective of this study is to use correlative quantitative nanomechanical methods to measure the nanomechanical properties of cement paste. The relative merits of the application of these three methods are specifically discussed for the determination of elastic modulus of cement paste from one-micrometer length scale to tens of nanometers scale. This fundamental understanding will be helpful in improving the basic behaviors of concrete, such as strength and durability.

\section{NANOMECHANICAL METHODS}

\section{Nanoindentation}

A static nanoindenation experiment was performed with a nanomechanical testing system equipped with an in-place imaging mode (Fig. 1). The nanoindentation instrument consists of a force-displacement transducer with electrostatic force actuation and displacement sensing electronics.

ACI Materials Journal, V. 111, No. 1-6, January-December 2014

MS No. M-2013-237.R2 received October 28, 2013, and reviewed under Institute publication policies. Copyright (C) 2014, American Concrete Institute. All rights reserved, including the making of copies unless permission is obtained from the copyright proprietors. Pertinent discussion including author's closure, if any, will be published ten months from this journal's date if the discussion is received within four months of the paper's print publication. 


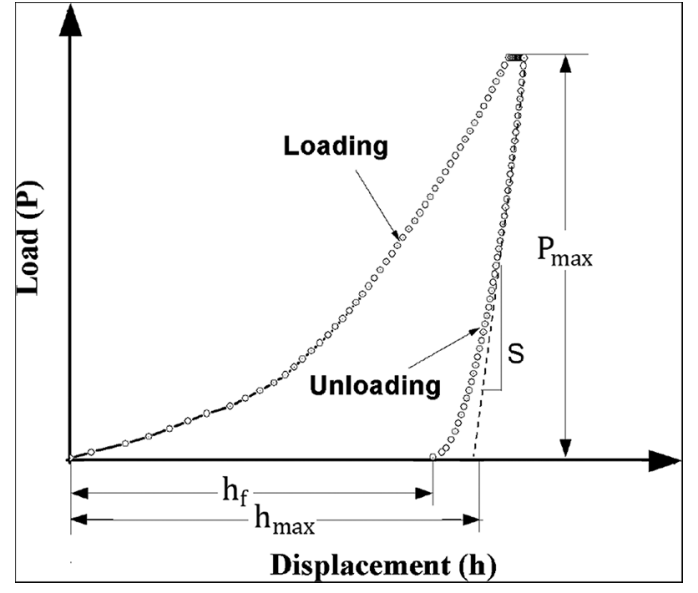

Fig. 2-Typical representation of indentation load versus indentation depth. ${ }^{19}$

A two-dimensional Berkovich indenter with a high elastic modulus is used. The suggested Poisson's ratio $v$ of the cement paste is $0.2 .^{25}$ The system is calibrated with standard quartz crystal before performing the actual indentation on the sample to ensure that the probe is not contaminated or damaged.

A typical representation of the indentation load versus indentation depth or displacement for an indentation experiment is shown in Fig. 2. The elastic modulus $E$ of the sample is calculated as follows

$$
\begin{gathered}
S=\frac{d P}{d h}=\frac{2}{\sqrt{\pi}} E_{r} \sqrt{A} \\
E_{s}=\left(1-v_{s}^{2}\right)\left[\frac{1}{E_{r}}-\frac{1-v_{i}^{2}}{E_{i}}\right]^{-1}
\end{gathered}
$$

where $P$ is the indentation load; $h$ is the indentation depth; $S$ is the initial unloading stiffness; $A$ is the projected contact area; $E_{r}$ is the reduced elastic modulus; $E_{s}$ and $v_{s}$ are elastic modulus and Poisson's ratio for the sample, respectively; and $E_{i}$ and $v_{i}$ are the corresponding parameters for the indenter, respectively. For the indenter used in this study, the elastic modulus $E_{i}=1140 \mathrm{GPa}(165,300 \mathrm{ksi})$, and the Poisson's ratio $v_{i}=0.07$.

\section{Modulus mapping}

Quantitative modulus mapping in the form of SPM images is acquired using the direct force modulation (nanoDMA) operating mode of the nanomechanical testing system. The schematic representation of the instrument configuration and dynamical mode are shown in Fig. 3. A cube-corner diamond tip is attached to a force-displacement transducer. As with nanoindentation, the system was calibrated with a standard quartz crystal. A lock-in amplifier is used to analyze the sample response, yielding displacement amplitude, and the phase shift between the contact force and the displacement. The contact stiffness and material damping are calculated from the amplitude and phase shift using a dynamic model. ${ }^{8,10}$

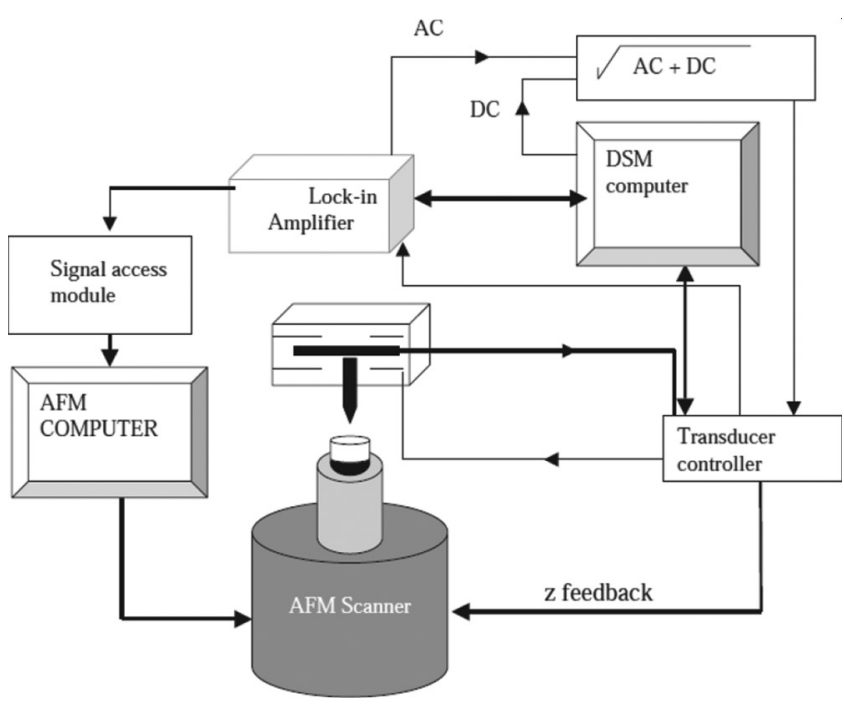

Fig. 3-Schematic of modulus mapping technique. ${ }^{10,11}$

To apply a load, a voltage is applied to generate an electrostatic force $F_{e}$. The mode of the direct force modulation applies a parallel loading configuration. The relevant equation of motion is

$$
F_{e}(t)=F_{0} \sin (\omega t)=m\left(\frac{d z^{2}}{d t^{2}}\right)+\beta\left(\frac{d z}{d t}\right)+k z
$$

where $\omega$ is the angular frequency; $F_{0}$ is the amplitude of the applied sinusoidal force; $m$ is the mass of the moving transducer; $\beta=\beta_{i}+\beta_{s}$ is the combined damping coefficient of the indenter and the sample; $k=k_{i}+k_{c}$ is the combined stiffness of the indenter and the sample; $z$ is the resulting sinusoidal displacement; and $t$ is time. The solution to this differential equation is

$$
z=z_{0} \sin (\omega t+\phi)
$$

where the displacement amplitude $z_{0}$ is given by the dynamical compliance function

$$
\frac{z_{0}}{F_{0}}=\left[\left(k-m \omega^{2}\right)^{2}+(\beta \omega)^{2}\right]^{-\frac{1}{2}}
$$

where the phase $\phi$ of the displacement is dictated by

$$
\tan (\varphi)=-\frac{\beta \omega}{k-m \omega^{2}}
$$

Determination of $m, \beta$, and $k_{i}$ is accomplished by nonlinear curve fitting of the dynamic compliance versus the frequency trace obtained in air. The storage $K^{\prime}$ and loss $K^{\prime \prime}$ components of the complex contact stiffness are extracted from the spatially correlated set of amplitude and phase images to generate quantitative stiffness maps

$$
K^{\prime}=k_{c}
$$


Table 1-Testing parameters of three techniques

\begin{tabular}{c|c|c|c}
\hline \multirow{2}{*}{ Probe type } & Nanoindentation & Modulus mapping & PeakForce QNM \\
\cline { 2 - 4 } & Berkovich (two-dimensional, 142.3 degrees) & Berkovich (one-dimensional, cube-corner) & AFM cantilever \\
\hline Tip radius & $600 \mathrm{~nm}(23.6 \mu \mathrm{in})$. & - & $5 \mathrm{~nm}(0.2 \mu \mathrm{in}$.) \\
\hline Tip material & Diamond & Diamond & Diamond \\
\hline Indent depth & 200 to $800 \mathrm{~nm}(8$ to $32 \mu \mathrm{in})$. & 7 to $12 \mathrm{~nm}(0.28$ to $0.47 \mu \mathrm{in})$. & 2 to $8 \mathrm{~nm}(0.08$ to $0.32 \mu \mathrm{in})$. \\
\hline Radius of curvature & - & $557.14 \mathrm{~nm}(22 \mu \mathrm{in})$. & - \\
\hline Applied force & $1200 \mu \mathrm{N}\left(270 \times 10^{-6} \mathrm{lb}\right)$ & $20 \mu \mathrm{N}\left(4.5 \times 10^{-6} \mathrm{lb}\right)$ & $50 \mathrm{nN}\left(11.2 \times 10^{-9} \mathrm{lb}\right)$ \\
\hline Deflection sensitivity & - & - & $70 \mathrm{~nm} / \mathrm{V}(2.8 \mu \mathrm{in} . / \mathrm{V})$ \\
\hline Maximum resolution & $800 \mathrm{~nm}(31.5 \mu \mathrm{in})$. & $60 \mathrm{~nm}(2.36 \mu \mathrm{in})$. & $5 \mathrm{~nm}(0.2 \mu \mathrm{in})$. \\
\hline
\end{tabular}

$$
K^{\prime \prime}=\beta_{c} \omega
$$

Rearrangement of the familiar equations of Hertzian theory yields the following relationship for the contact radius $a$

$$
a=\sqrt{\frac{3 F R}{2 K^{\prime}}}
$$

where $F$ corresponds to the nominal contact force, and $R$ is the tip radius. The modulus then can be calculated as

$$
E_{s}=\frac{1}{2} \frac{K^{\prime}}{a}
$$

In static nanoindentation, a minimum separation of $3 \mu \mathrm{m}$ (118 $\mu \mathrm{in}$.) between indentations is required to avoid possible interactions between adjacent indentions. The modulus mapping technique in the form of scanning probe microscopy (SPM) images, however, can overcome these shortcomings. This is because the material under the tip is probed within the elastic region, and once the tip force is removed, the material can fully recover without local residual stress or permanent deformation.

\section{PeakForce QNM}

Recently, a high resolution method called PeakForce QNM was developed to study the quantitative mechanical properties of cement-based materials at approximately 10 nm $(0.4 \mu$ in. $)$ resolution. ${ }^{14,26,27}$ PeakForce QNM is a mode with improved force resolution combined with real time calculation of elastic modulus at each surface contact, which can detect local elastic modulus. This technique can provide compositional mapping of a complex composite material while providing high resolution. In PeakForce tapping, the probe and sample are intermittently brought together (similar to tapping mode) to contact the surface for a short period, which eliminates lateral forces. Unlike tapping mode, where the feedback loop keeps the cantilever vibration amplitude as a constant, PeakForce tapping controls the maximum force on the tip. This protects the tip and sample from damage while allowing the tip sample contact area to be minimized.

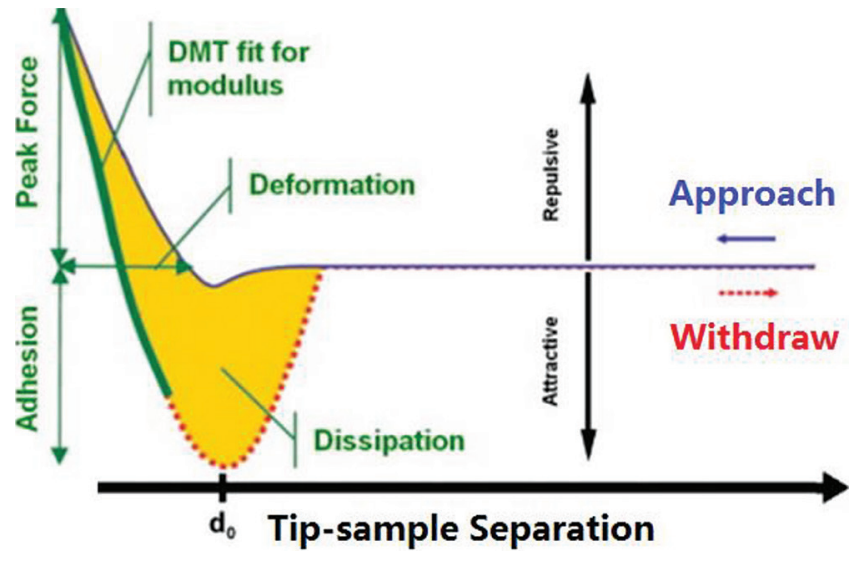

Fig. 4-PeakForce QNM schematic. ${ }^{3,13}$

For the PeakForce QNM, the schematic diagram of the collected force-separation curve is shown in Fig. 4. To elucidate the elastic properties from the PeakForce QNM, the Derjaguin-Muller-Toporov (DMT) model can be used for the estimation of reduced elastic modulus. ${ }^{28}$ The forces during the tip-surface interaction can be described by

$$
F_{\text {int }}=\frac{4}{3} E^{*} \sqrt{R d^{3}}+F_{a d h}
$$

where $F_{\text {int }}$ is the tip-sample force during the tip-surface interaction; $E^{*}$ is the combined elastic modulus of the tip and the sample; $R$ is the tip radius; $d$ is the sample deformation; and $F_{\text {adh }}$ is the adhesion force during the contact. The elastic modulus of the sample $E_{s}$ can be derived from the following equation

$$
\frac{1}{E^{*}}=\frac{1-v_{s}^{2}}{E_{s}}+\frac{1-v_{t i p}^{2}}{E_{t i p}}
$$

where $v_{s}$ is the Poisson's ratio of the sample; $v_{t i p}$ is the Poisson's ratio of the tip; $E_{s}$ is the elastic modulus of the sample; and $E_{t i p}$ is the elastic modulus of the tip. Calibration was also performed by the relative method ${ }^{13}$ using a standard quartz crystal. The testing parameters of the three techniques are listed in Table 1. 


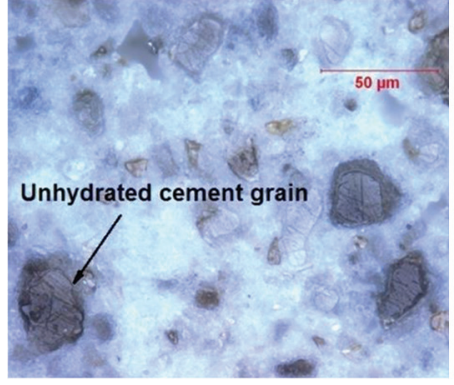

(a)

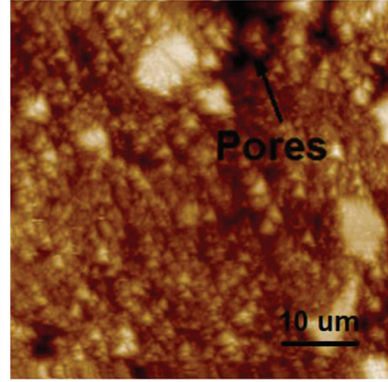

(b)
Fig. 5-Cement paste sample after polishing: (a) optical image; and (b) AFM image.

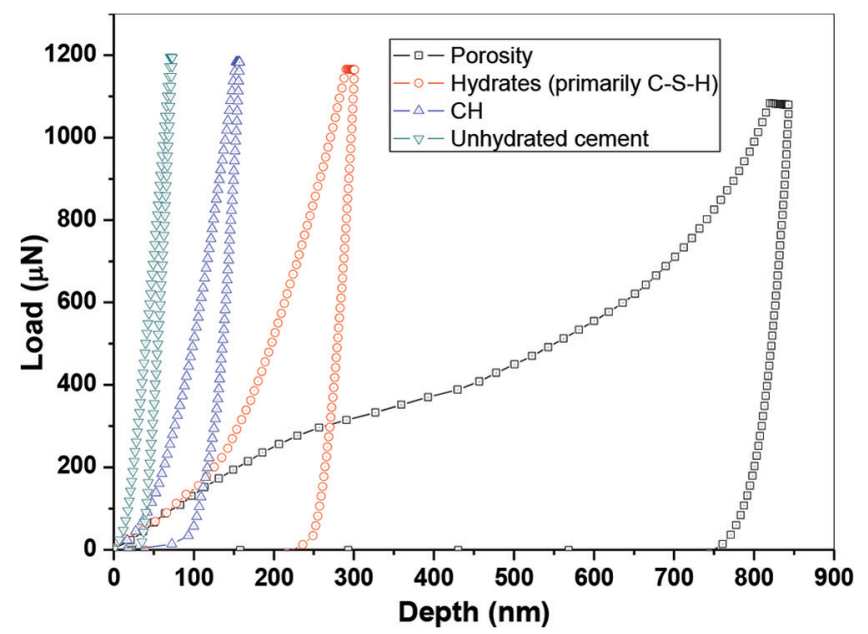

Fig. 6-Load-depth diagrams of different phases in cement paste. $^{7,20}$ (Note: $1 \mu N=0.225 \times 10^{-6} \mathrm{lb} ; 1 \mathrm{~nm}=0.04 \mu \mathrm{in}$.)

\section{SAMPLE PREPARATION}

A $5 \mathrm{~mm}(0.2$ in.) thick $10 \times 10 \mathrm{~mm}(0.4 \times 0.4$ in. $)$ block of hardened cement paste with a water-cement ratio of 0.40 was produced from Type I portland cement. The cement paste was cured for 90 days under $25^{\circ} \mathrm{C}\left(77^{\circ} \mathrm{F}\right)$ and $95 \%$ relative humidity condition. The sample was initially ground on paper disks with gradation of grits. One polishing method can provide repeated success by long durations of polishing under light load. An auto-polisher was used with diamond suspensions in ethanol with gradations. Each step lasted approximately 30 minutes. In the following steps, diamond lapping films with gradations were used. ${ }^{1,21,24}$ The completed polished surface is shown in Fig. 5(a). Figure 5(b) shows the surface topography of a square region of the polished sample as acquired by high-resolution tapping mode AFM. The root-mean-square (RMS) of the surface roughness based on the topography map is $93.9 \pm 20 \mathrm{~nm}(3.7 \pm 0.79 \mu \mathrm{in}$.) for a scan size of $50 \times 50 \mu \mathrm{m}(0.002 \times 0.002$ in.). The RMS value can be used to evaluate the surface roughness because there is no standard criterion of roughness of cement pastes for nanomechanical testing due to the inherent roughness of hardened cement pastes, particularly which would be applicable to the three methods presented. ${ }^{29}$ For nanoindentation, the most commonly used method for nanomechanical characterization of cement hydration products is Miller et al., ${ }^{30}$ who reported the RMS roughness measured over an area with one side 200 times the average depth of indenta-
Table 2-Typical nanomechanical properties for indented phases $3,7,20$

\begin{tabular}{c|c|c|c}
\hline Material phase & $\begin{array}{c}\text { Maximum } \\
\text { depth, nm }\end{array}$ & $\begin{array}{c}\text { Elastic } \\
\text { modulus, GPa }\end{array}$ & $\begin{array}{c}\text { Hardness, } \\
\text { GPa }\end{array}$ \\
\hline Porosity & $843.1 \pm 127.5$ & $4.75 \pm 4.78$ & $0.04 \pm 0.21$ \\
\hline $\begin{array}{c}\text { Hydrates (primarily } \\
\text { C-S-H) }\end{array}$ & $300.9 \pm 97.6$ & $20.31 \pm 12.59$ & $0.64 \pm 0.45$ \\
\hline Calcium hydroxide (CH) & $157.2 \pm 50.0$ & $55.75 \pm 15.80$ & $1.51 \pm 0.67$ \\
\hline $\begin{array}{c}\text { Unhydrated cement } \\
\text { particle }\end{array}$ & $73.3 \pm 37.4$ & $89.47 \pm 19.19$ & $4.52 \pm 1.57$ \\
\hline
\end{tabular}

Note: $1 \mathrm{~nm}=0.04 \mu$ in.; $1 \mathrm{GPa}=145 \mathrm{ksi}$.

tion should be less than one fifth of the average indentation depth. The roughness of the samples tested in this study is sufficiently low and is comparable to those obtained by other investigators. ${ }^{3,430}$

\section{RESULTS AND DISCUSSION}

\section{Nanoindentation}

Nanoindentation was performed on the cement paste sample. During the first 5 seconds, the indenter was driven into the sample at a $240 \mu \mathrm{N} / \mathrm{s}(54 \mu \mathrm{lb} / \mathrm{s})$ loading rate. After reaching the maximum load of $1200 \mu \mathrm{N} / \mathrm{s}(270 \mu \mathrm{lb} / \mathrm{s})$, the indenter was held in place for 2 seconds to reduce the creep effect before unloading at a rate of $240 \mu \mathrm{N} / \mathrm{s}(54 \mu \mathrm{lb} / \mathrm{s})$. Indentations were made on separate $15 \times 15 \mu \mathrm{m}(591 \mathrm{x}$ $591 \mu \mathrm{in}$.$) and 100 \times 100 \mu \mathrm{m}(0.004 \times 0.004 \mathrm{in}$.) regions to compare profiles and cover more phases for statistical analysis.

Figure 6 shows typical loading and unloading curves during indentations on different phases of cement paste. The tested indentation modulus ${ }^{4,7}$ for porosity, hydrates (predominantly calcium silicate hydrate [C-S-H]), calcium hydroxide $(\mathrm{CH})$, and unhydrated cement grains are given in Table 2 . Figures 7 and 8 are contour maps of indentation modulus for the area of $100 \times 100 \mu \mathrm{m}(0.004 \times 0.004$ in. $)$ and $15 \times$ $15 \mu \mathrm{m}(591 \times 591 \mu \mathrm{in}$.), respectively. Results indicate the general heterogeneity of mechanical properties in the tested sample, which might be due to the different phases shown in Fig. 6 . The areas with a relatively high indentation modulus value, higher than $50 \mathrm{GPa}$ (7252 ksi), would be unhydrated or partially hydrated cement particles. This value is in agreement with the values of the elastic modulus measured experimentally for partially hydrated clinker residues by other researchers. ${ }^{3,6}$ The regions with indentation modulus values ranging from 10 to $50 \mathrm{GPa}$ (1450 to $7252 \mathrm{ksi}$ ) are hydration products. ${ }^{6,21,31-33}$ The lower values of indentation modulus, less than $10 \mathrm{GPa}(1450 \mathrm{ksi})$, are likely due to porous regions in the cement paste..$^{20,21}$

Figure 9 shows the indentation modulus probability distribution to compare the statistical analysis of two different scanned areas. The peak modulus of the probability plot in the $15 \times 15 \mu \mathrm{m}(591 \times 591 \mu \mathrm{in}$.) area is higher than that in the $100 \times 100 \mu \mathrm{m}(0.004 \times 0.004 \mathrm{in}$.). The distribution of phases is clearly influenced by the size of the scanned area: for the larger area, the amount of cement clinker and porosity phase increase, which results in a greater variation in the inden- 

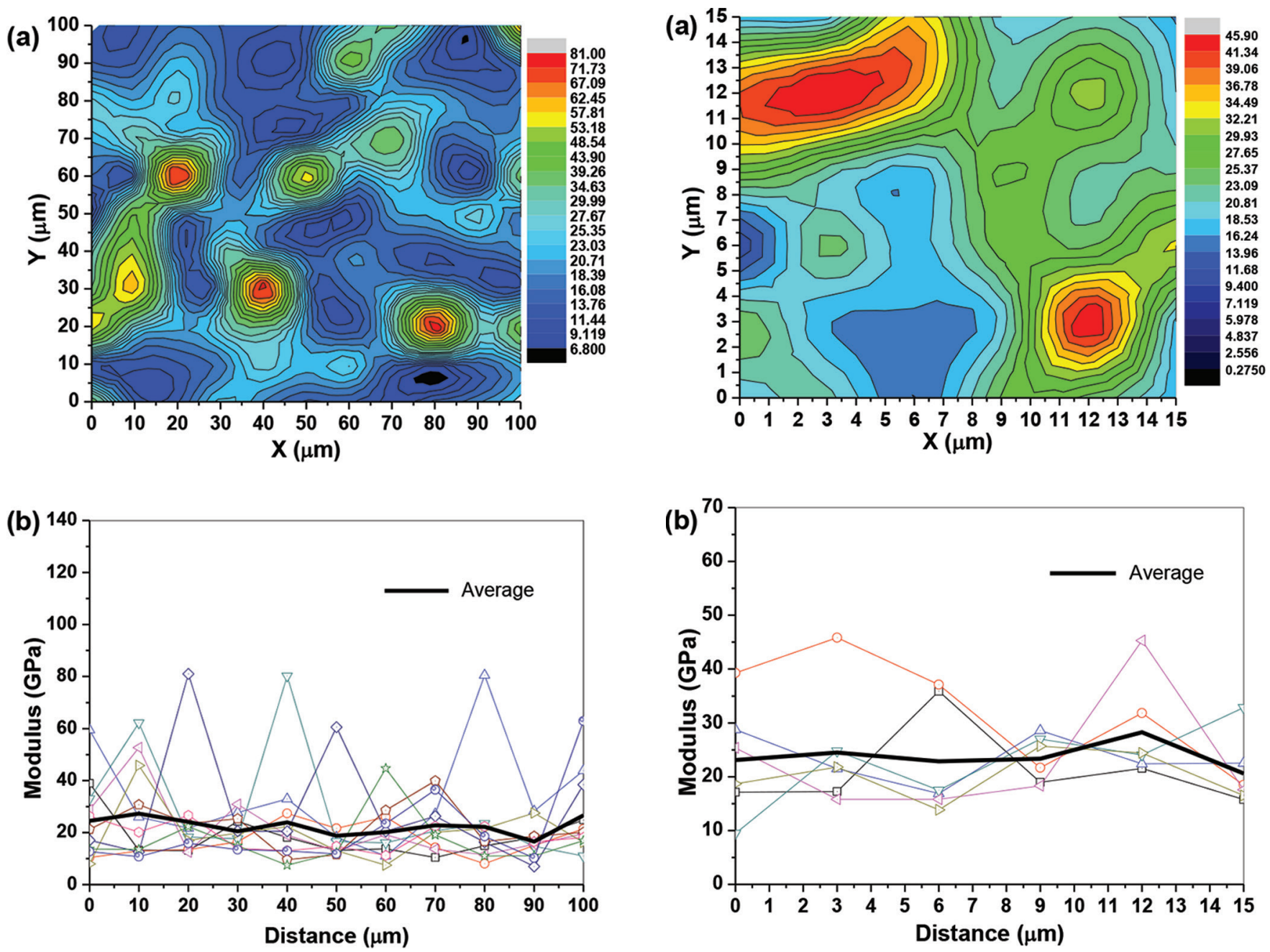

Fig. 7-Elastic modulus of cement paste obtained by nanoindentation (100 x $100 \mu \mathrm{m})$ : (a) indentation modulus contour map; and (b) indentation modulus distribution. (Note: $1 \mu \mathrm{m}$ $=39.4$ uin.; $1.0 \mathrm{GPa}=145 \mathrm{ksi}$.)

tation modulus distribution. Although many studies have been conducted on the nanomechanical properties of phases in cement paste, little has been reported to characterize and provide quantitative measurements considering different sizes of the investigated area.

\section{Modulus mapping}

When switching the testing mode to study the nanomechanical properties of cement paste by modulus mapping and nanoindentation in the indenter, the position of the tested sample remains unchanged. As the sample surface could potentially be damaged by the larger force required by static nanoindentation, modulus mapping was always performed first on the sample. Figure 10 shows topographical maps for the areas $15 \times 15 \mu \mathrm{m}(591 \times 591 \mu \mathrm{in}$.) and $5 \mathrm{x}$ $5 \mu \mathrm{m}(197$ x $197 \mu \mathrm{in}$.), respectively, which were obtained by modulus mapping. It reveals that cement paste is composed of different types of phases.

Figure 11(a) shows the elastic modulus contour maps for the area of $15 \times 15 \mu \mathrm{m}$ (591 x $591 \mu \mathrm{in}$.). From Fig. 11(b), it is found that quantitative modulus variations in modulus mapping are larger than those in nanoindentation. The range

Fig. 8-Elastic modulus of cement paste obtained by nanoindentation (15 x $15 \mu \mathrm{m})$ : (a) contour map of indentation modulus; and (b) indentation modulus distribution. (Note: $1 \mu \mathrm{m}=39.4 \mu \mathrm{in}$.; $1.0 \mathrm{GPa}=145 \mathrm{ksi}$.)
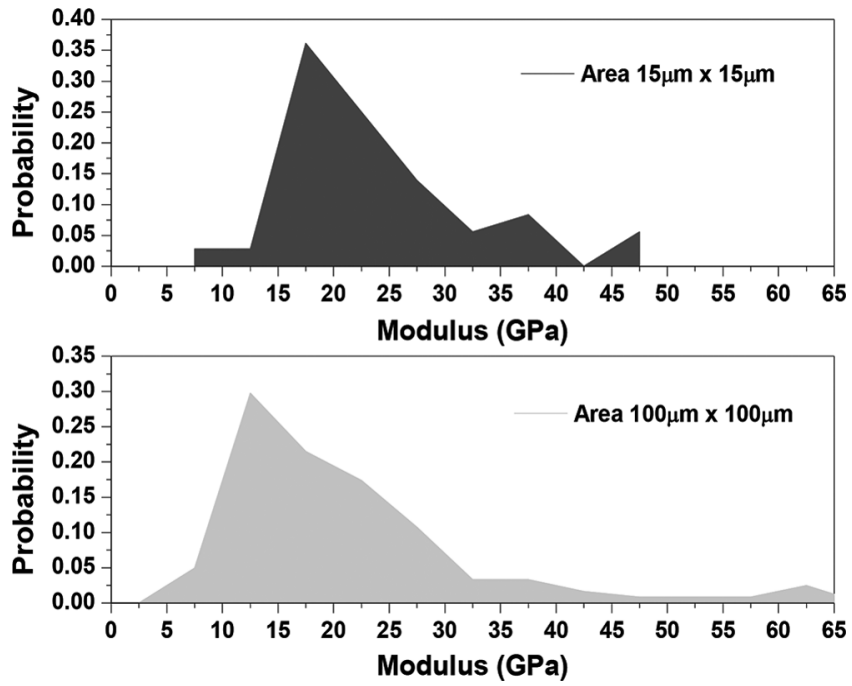

Fig. 9-Statistical analysis of modulus (bin size = $5.0 \mathrm{GPa}$ ). (Note: $1 \mu \mathrm{m}=39.4$ uin.; $1.0 \mathrm{GPa}=145 \mathrm{ksi}$.) 

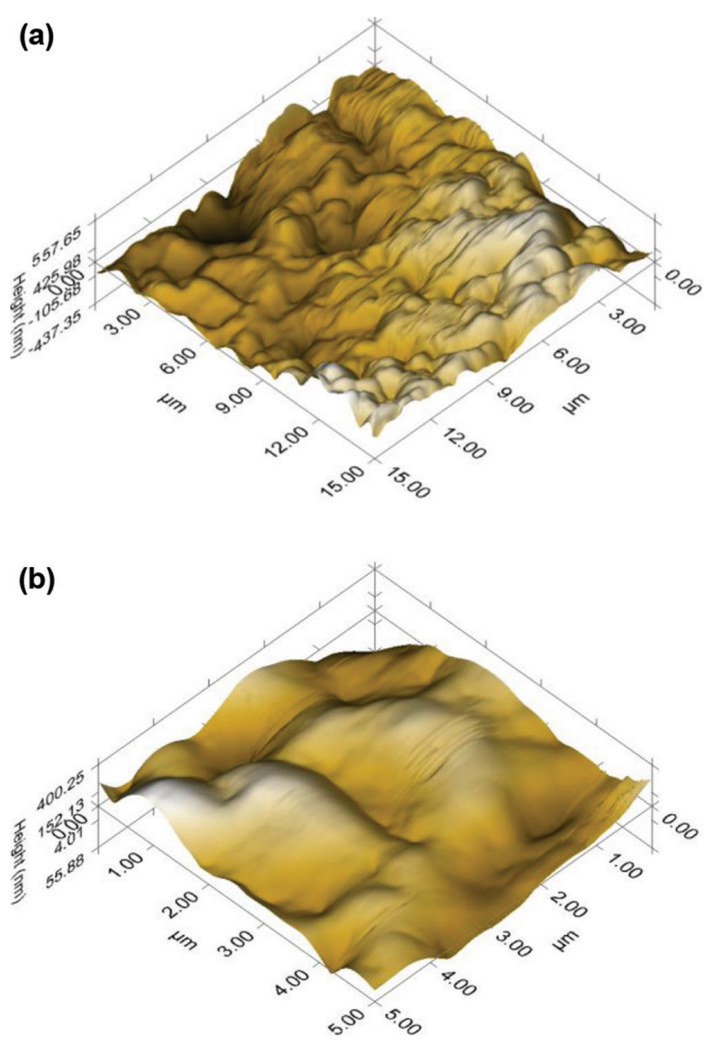

Fig. 10 - Surface topography obtained by modulus mapping: a) $15 \times 15 \mu \mathrm{m}$; and b) $5 \times 5 \mu \mathrm{m}$. (Note: $1 \mu \mathrm{m}=39.4 \mu \mathrm{in}$.)

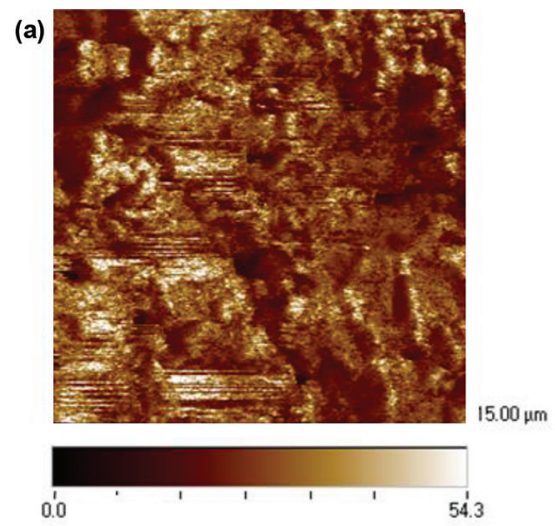

of elastic moduli, from 0.2 to $124.5 \mathrm{GPa}$ (29 to $18,057 \mathrm{ksi}$ ), is found to be significantly greater than that obtained by static nanoindentation. ${ }^{10,34}$ The results for the scanned area 5 x $5 \mu \mathrm{m}(197 \times 197 \mu$ in. $)$ are shown in Fig. 12. The results reveal that the modulus mapping technique is more sensitive than static nanoindentation, as indicated by the higher spatial resolution. Significant local elastic modulus variations were observed at the sample surface, which was comprised of different phases and interfaces between hydration products. Moreover, clear abrupt changes in the elastic modulus were measured, and found to be due to the interfaces between the pores and different hydration products. The modulus probability histograms for two different areas are presented in Fig. 13. It is clear that the peak modulus in the probability plot is slightly higher for the area $5 \times 5 \mu \mathrm{m}(197 \times 197 \mu \mathrm{in}$.) than for $15 \times 15 \mu \mathrm{m}(591 \times 591 \mu \mathrm{in}$. $)$.

\section{PeakForce QNM}

Modulus mapping and PeakForce QNM were performed on two separate devices. Thus, when switching from one method to the other, it is necessary to confirm that they are each performed at the same position on the sample. To do this, high-resolution images were captured during the test, and image analysis was performed to measure the distance and adjust the test position accordingly.

Figure 14 shows the $512 \times 512$ pixel topography images of two scanning areas, $5 \times 5 \mu \mathrm{m}$ and 1 x $1 \mu \mathrm{m}(197 \times 197 \mu \mathrm{in}$. and $39.4 \times 39.4 \mu \mathrm{in}$.), of a cement paste sample obtained

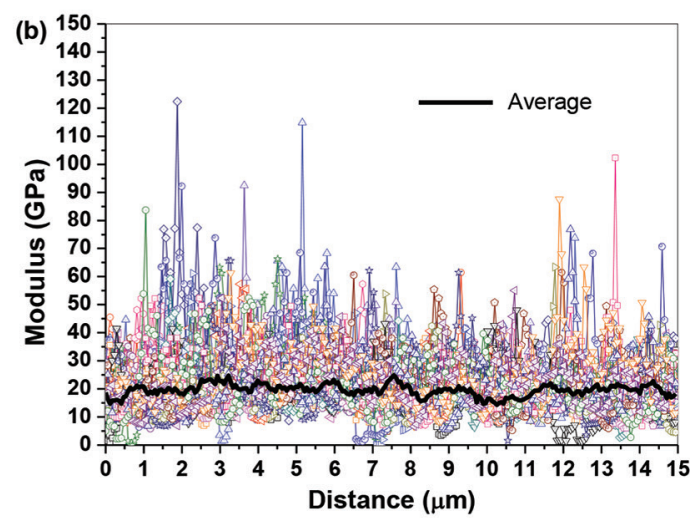

Fig. 11-Elastic modulus obtained by modulus mapping (15 x $15 \mu \mathrm{m})$ : (a) modulus contour map; and (b) elastic modulus distribution. (Note: $1 \mu \mathrm{m}=39.4$ in.; $1.0 \mathrm{GPa}=145 \mathrm{ksi}$.)
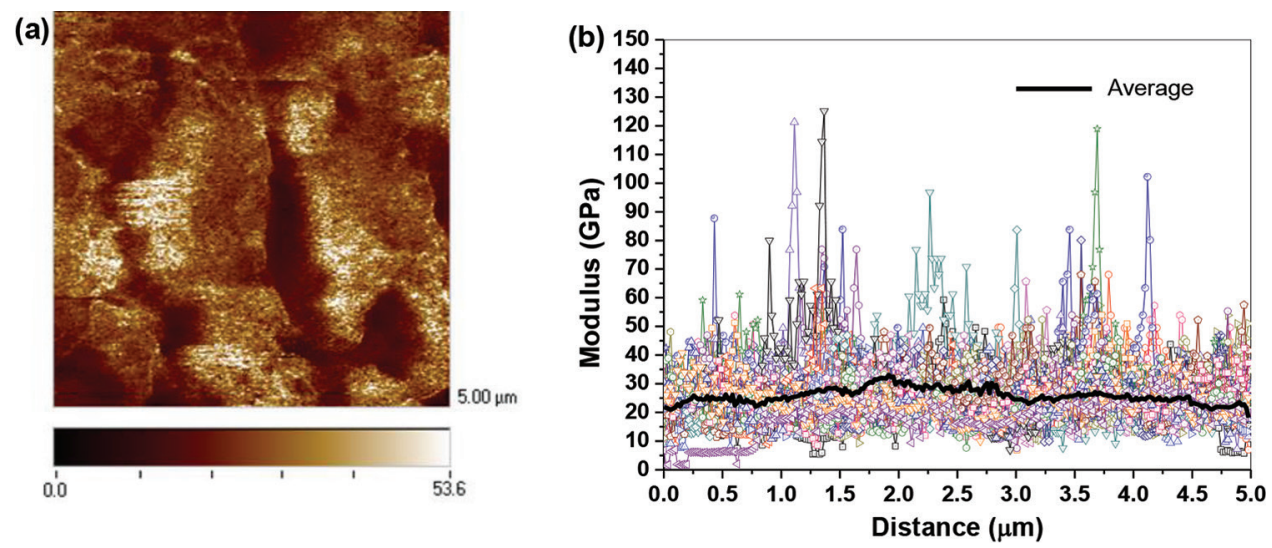

Fig. 12-Elastic modulus obtained by modulus mapping (5 x $5 \mu \mathrm{m}$ ). (Note: $1 \mu \mathrm{m}=39.4 \mu \mathrm{in}$.; $1.0 \mathrm{GPa}=145 \mathrm{ksi}$.) 

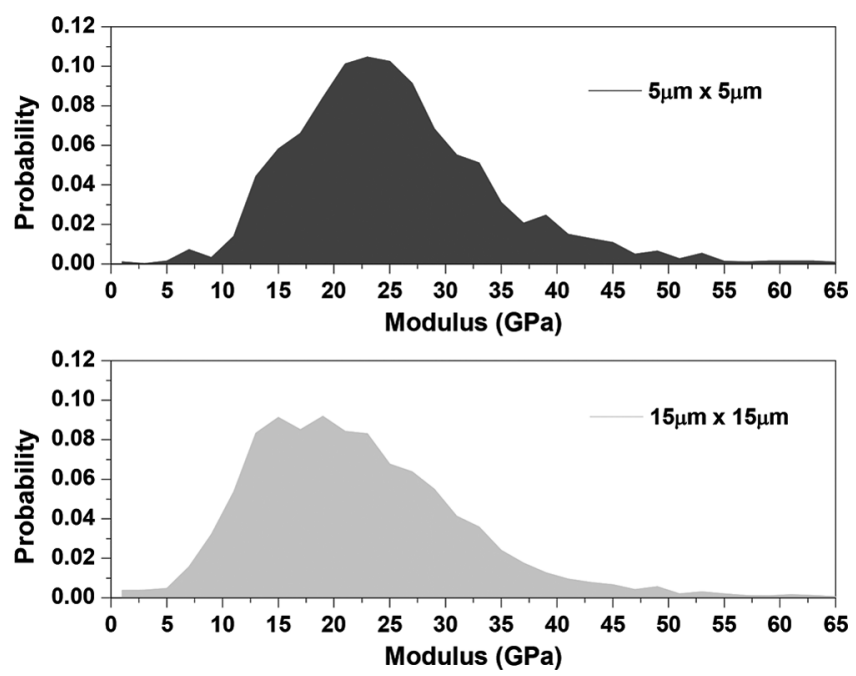

Fig. 13-Statistical analysis of modulus (bin size $=2.0$ GPa). (Note: $1 \mu \mathrm{m}=39.4 \mu \mathrm{in}$.; $1.0 \mathrm{GPa}=145 \mathrm{ksi}$.)

(a)

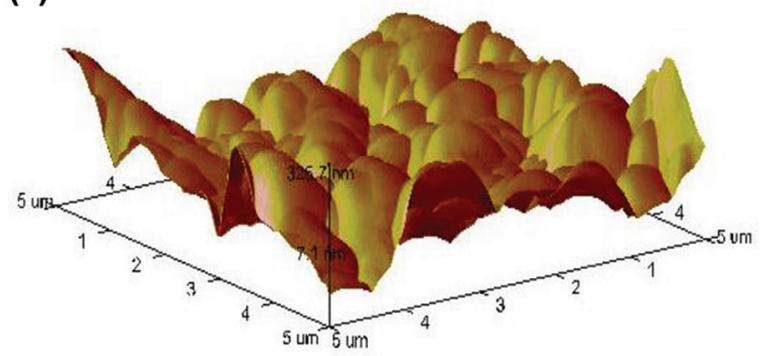

(b)

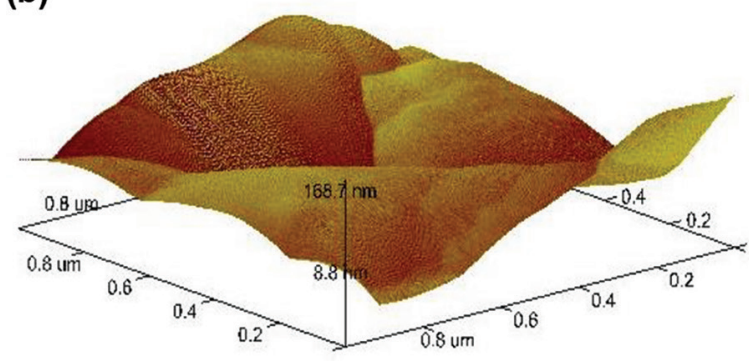

Fig. 14-Surface topography obtained by PeakForce QNM: a) $5 \times 5 \mu \mathrm{m}$; and b) $1 \times 1 \mu \mathrm{m}$. (Note: $1 \mu \mathrm{m}=39.4 \mu \mathrm{in}$.) by PeakForce QNM. The microstructural and nanostructural contrast can be observed clearly in the surface topography. It should be noted that the intrinsic porosity in cement paste poses some constraint on the use of PeakForce QNM, for which some noise could be expected. The images indicate that the height distribution of local areas varies widely for different measuring areas. The values of all local roughness, however, are actually sufficiently low for PeakForce QNM testing. ${ }^{3,13}$ The topography images also demonstrate that the cement paste is a granular material, where the sub-micron scale grains or basic nanoscale units pack together densely. ${ }^{35-39}$

Clear nanostructural features for the area of $5 \times 5 \mu \mathrm{m}$ (197 x $197 \mu \mathrm{in}$.) that can be discerned in the contour image are presented in Fig. 15. In these images, the porosity and the interfaces between nanoscale grains appear dark with a lower elastic modulus. To analyze the nanostructure and nanomechanical properties in more detail, a smaller area of $1 \times 1 \mu \mathrm{m}(39.4 \times 39.4 \mu \mathrm{in}$.) was studied, as shown in Fig. 16. Based on previous studies, the elastic modulus of the measuring area identified as the pore space is typically below $10.0 \mathrm{GPa}(1450 \mathrm{ksi})$, while the elastic modulus of the measuring areas identified as hydration products were found to vary approximately between 10.0 and $50.0 \mathrm{GPa}$ (1450 and $7252 \mathrm{ksi}){ }^{7,40,41}$ The probabilities of elastic modulus for two different scanning areas are shown in Fig. 17. It demonstrates that the probability distributions do not seem to provide a very clear indication for the occurrence of different types of $\mathrm{C}-\mathrm{S}-\mathrm{H}$. When comparing the analogous probability results of the two different scanning areas, the peak modulus value of the probability plot for the area of 5 x $5 \mu \mathrm{m}(197 \times 197$ $\mu$ in.) appears to be close to that of $1 \times 1 \mu \mathrm{m}(39.4 \times 39.4$ $\mu \mathrm{in}$.), which is found to be approximately $25.0 \pm 2.0 \mathrm{GPa}$ $(3626 \pm 290 \mathrm{ksi})$.

As shown in Fig. 18, it is suggested that the PeakForce QNM technique can reveal the different types of grains in hardened cement paste. This observation also highlights the advantage of evaluating the interfaces between grains by detecting the elastic modulus distribution. According to the quantitative modulus value of the presented results, there is a clear jump in the elastic modulus distribution across the interfaces between grains. The elastic modulus of the grains themselves, however, typically exhibits a constant value. Moreover, abrupt changes in the elastic modulus across the interfaces were clearly observed. The information stemming
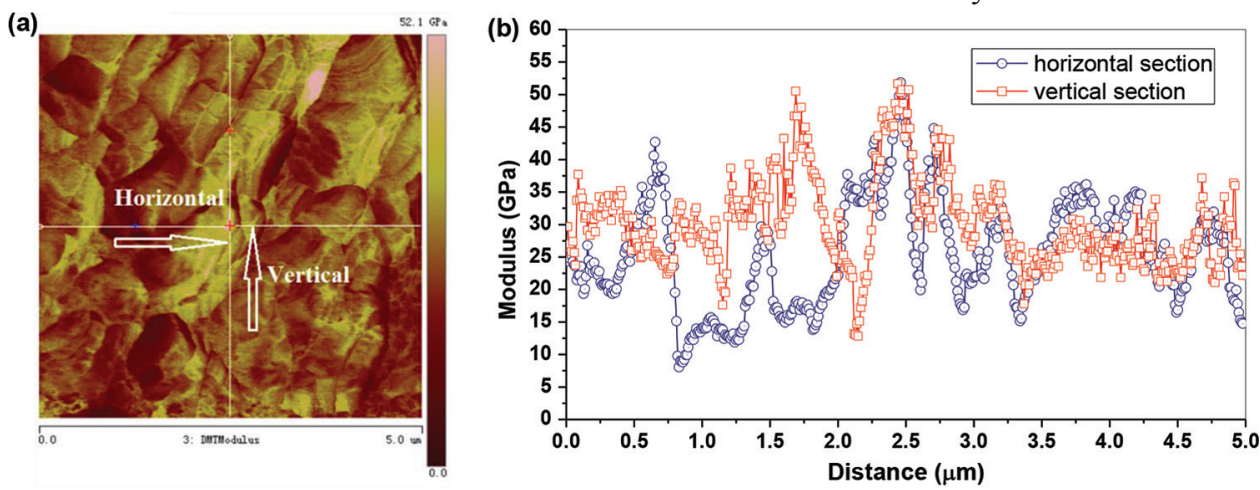

Fig. 15-Elastic modulus obtained by PeakForce QNM (5 x $5 \mu \mathrm{m})$ : (a) modulus contour map; and (b) modulus distribution. (Note: $1 \mu \mathrm{m}=39.4 \mu \mathrm{in}$.; $1.0 \mathrm{GPa}=145 \mathrm{ksi}$.) 

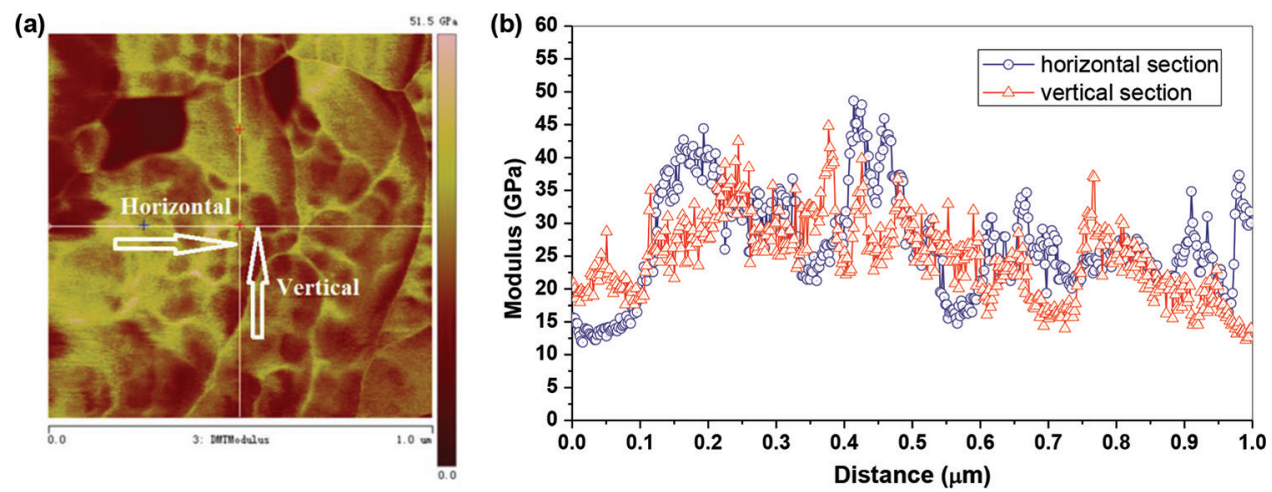

Fig. 16-Elastic modulus obtained by PeakForce QNM (1 x $1 \mu \mathrm{m})$ : (a) modulus contour map; and (b) modulus distribution. (Note: $1 \mu m=39.4$ нin.; $1.0 \mathrm{GPa}=145 \mathrm{ksi}$.)
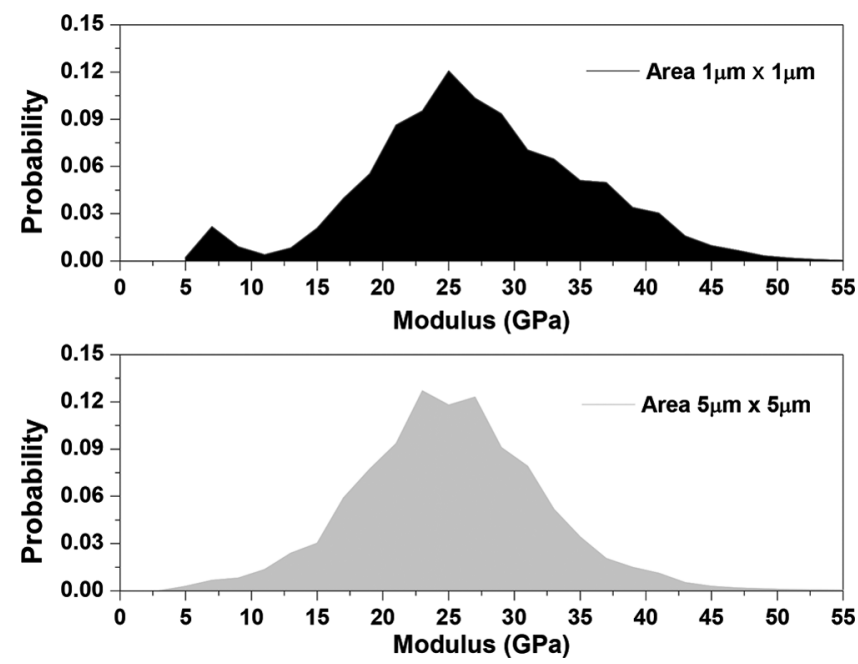

Fig. 17-Statistical analysis of modulus (bin size=2.0 GPa). (Note: $1 \mu \mathrm{m}=39.4$ uin.; $1.0 \mathrm{GPa}=145 \mathrm{ksi}$.)

from the PeakForce QNM technique can reasonably identify the grains with sizes from 20 to $400 \mathrm{~nm}(0.79$ to $15.8 \mu \mathrm{in}$.) in the nanostructure. To provide quantitative measurements of the interface thickness between grains, radial lines (interface A-A, B-B, and C-C) across the grain boundaries were applied to indicate the elastic modulus variation corresponding to the interface thickness. By definition, the interface starts from the point where the elastic modulus begins to change from that of one grain, and extends to another point where the local elastic modulus is equal to that of another grain. The distance between these two points corresponds to the interface thickness. The thickness of the interface obtained by averaging these lines, and the most probable thickness of the interface between grains, was found to be $15 \pm 5 \mathrm{~nm}$ $(0.59 \pm 0.2 \mu \mathrm{in}$.$) .$

\section{CONCLUSIONS}

Based on the analyses and comparisons among the results from nanoindentation, modulus mapping, and PeakForce QNM, the following conclusions can be drawn:

1. The average modulus measured by static nanoindentation is higher than those measured by the modulus mapping technique and PeakForce QNM, which may be due to the confinement effect and the plastic deformation in the nanoindentation.
2. Compared with static nanoindentation, modulus mapping allows for evaluation of local mechanical properties within smaller measuring areas at the nanoscale. Moreover, modulus mapping avoids influence on elastic modulus due to possible interaction between adjacent indentations.

3 . The average elastic modulus and probability distribution obtained from PeakForce QNM are typically consistent with those measured with quantitative modulus mapping. Compared with the modulus mapping, PeakForce QNM can provide local mechanical properties with a higher spatial resolution.

4. Different types of grains are detected with the quantitative elastic modulus value. Obvious local interfaces between grains could be observed from the abrupt change in the mechanical properties distribution when crossing the boundary between different phase grains.

5. It is proven that cement paste is a granular material, in which the sub-micron scale grains or basic nanoscale units pack together. Moreover, the correlative nanomechanical methods provide an efficient tool for identification of properties and particle sizes of grains, and the interfaces between grains.

\section{AUTHOR BIOS}

ACI member Wengui Li is an Assistant Professor in the College of Civil Engineering at Hunan University, Changsha, Hunan, China. He received his PhD from Tongii University, Shanghai, China, in 2013, and was a Visiting Researcher at the Center for Advanced Cement-Based Materials at Northwestern University, Evanston, IL from Nov. 2010 to Jan. 2013. He is a member of ACI Committee 555, Concrete with Recycled Materials. His research interests include mechanical behaviors of cement-based materials and computer simulation.

Jianzhuang Xiao is a Professor in the Building Engineering Department at Tongji University, and the Director of the Recycled Concrete Committee in China. His research interests include the mechanical and structural behaviors of recycled concrete.

ACI member Shiho Kawashima is an Assistant Professor in the Department of Civil Engineering and Engineering Mechanics at Columbia University, New York, NY. Her research interests include nanomodification, nanocharacterization of cementitious materials, and sustainable infrastructural materials.

Gajendra S. Shekhawat is a Research Associate Professor, NIFTI Facility Manager, at the International Institute for Nanotechnology, Northwestern University. His research interests include nanomaterials synthesis and characterization, surface characterization methods, and quantitative and qualitative scanning probe microscopy. 

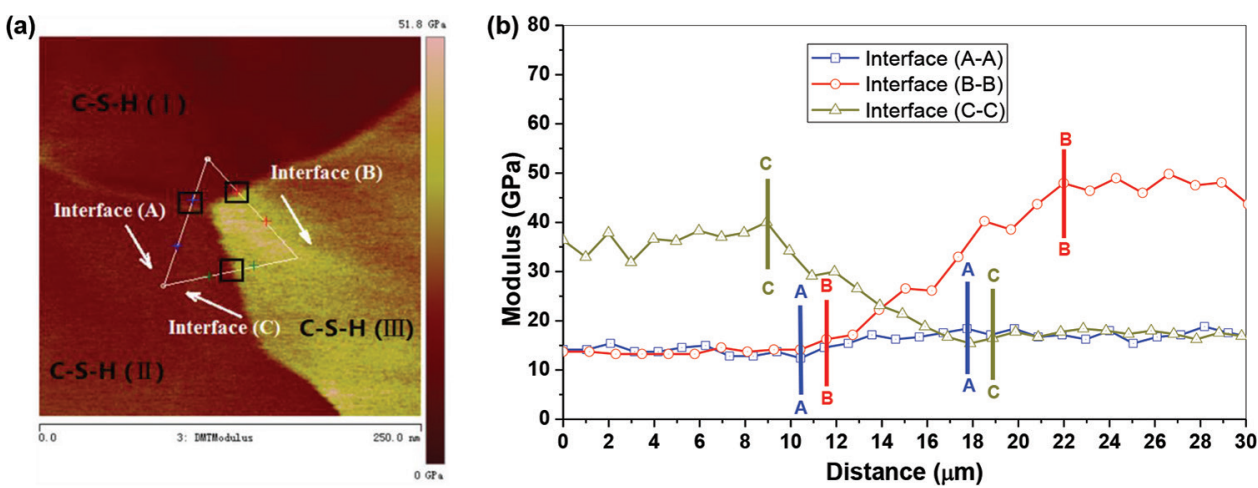

Fig. 18-DMT modulus obtained by PeakForce QNM (0.25 x $0.25 \mu \mathrm{m})$ : (a) interface position; and (b) modulus distribution. (Note: $1 \mu \mathrm{m}=39.4$ uin.; $1.0 \mathrm{GPa}=145 \mathrm{ksi}$.)

Surendra P. Shah, FACI, is the Walter P. Murphy Professor of Civil Engineering at Northwestern University. He is a member of ACI Committees 215, Fatigue of Concrete; 363, High-Strength Concrete; 440, Fiber-Reinforced Polymer Reinforcement; 544, Fiber-Reinforced Concrete; 548, Polymers and Adhesives for Concrete; 549, Thin Reinforced Cementitious Products and Ferrocement; S803, Faculty Network Coordinating Committee; and Joint ACI-ASCE Committee 446, Fracture Mechanics of Concrete.

\section{ACKNOWLEDGMENTS}

The authors would like to acknowledge the financial support from the National Natural Science Foundation of China (51178340). All tests were performed in the NIFTI facility of the NUANCE Center at Northwestern University. The first author would like to thank the China Scholarship Council (CSC) and the Fund Support Project for Young Faculty at Hunan University (531107040800). The authors also gratefully thank G. Lomboy and D. J. Corr.

\section{REFERENCES}

1. Mondal, P.; Shah, S. P.; and Marks, L. D., "Nanoscale Characterization of Cementitious Materials," ACI Materials Journal, V. 105, No. 2, Mar.-Apr. 2008, pp. 174-179.

2. Kim, J. H.; Mondal, P.; and Shah, S. P., "Cement-Based Materials Characterization at Nanoscale: Nanoindentation and Ultrasonic Atomic Force Microscopy (AFM)," Advances in the Material Science of Concrete, SP-270, American Concrete Institute, Farmington Hills, MI, 2010, pp. $67-76$.

3. Trtik, P.; Kaufmann, J.; and Volz, U., "On the Use of Peak-Force Tapping Atomic Force Microscopy for Quantification of the Local Elastic Modulus in Hardened Cement Paste," Cement and Concrete Research, V. 42, No. 1, 2012, pp. 215-221.

4. Jones, C. A.; Grasley, Z. C.; and Ohlhausen, J. A., "Measurement of Elastic Properties of Calcium Silicate Hydrate with Atomic Force Microscopy," Cement and Concrete Composites, V. 34, No. 4, 2012, pp. 468-477.

5. Jones, C. A., and Grasley, Z. C., "Short-Term Creep of Cement Paste during Nanoindentation," Cement and Concrete Composites, V. 33, No. 1, 2011, pp. 12-18.

6. Davydov, D.; Jirásek, M.; and Kopecký, L., "Critical Aspects of Nano-Indentation Technique in Application to Hardened Cement Paste," Cement and Concrete Research, V. 41, No. 1, 2011, pp. 20-29.

7. Sorelli, L.; Constantinides, G.; Ulm, F.-J.; and Toutlemonde, F., "The Nano-Mechanical Signature of Ultra High Performance Concrete by Statistical Nanoindentation Techniques," Cement and Concrete Research, V. 38, No. 12,2008 , pp. 1447-1456.

8. Syed Asif, S. A.; Wahl, K. J.; and Colton, R. J., "Nanoindentation and Contact Stiffness Measurement Using Force Modulation with a Capacitive Load-Displacement Transducer," The Review of Scientific Instruments, V. 70, No. 5, 1999, pp. 2408-2413.

9. Syed Asif, S. A.; Wahl, K. J.; Colton, R. J.; and Warren, O. L., "Quantitative Imaging of Nanoscale Mechanical Properties Using Hybrid Nanoindentation and Force Modulation," Journal of Applied Physics, V. 90, No. 3, 2001, pp. 1192-1200.

10. Balooch, G.; Marshall, G. W.; Marshall, S. H.; Warren, O. L.; Asif, S. A. S.; and Balooch, M., "Evaluation of a New Modulus Mapping Technique to Investigate Microstructural Features of Human Teeth," Journal of Biomechanics, V. 37, No. 8, 2004, pp. 1223-1232.
11. Uskokovic, P. S.; Tang, C. Y.; Tsui, C. P.; Ignjatovic, N.; and Uskokovic, D. P., "Micromechanical Properties of Ahydroxyapatite/ Poly-L-Lactidebiocomposite Using Nanoindentation and Modulus Mapping," Journal of the European Ceramic Society, V. 27, No. 2-3, 2007, pp. 1559-1564.

12. Young, T. J.; Monclus, M. A.; Burnett, T. L.; Broughton, W. R.; Ogin, S. L.; and Smith, P. A., "The Use of the PeakForce ${ }^{\mathrm{TM}}$ Quantitative Nanomechanical Mapping AFM-Based Method for High-Resolution Young's Modulus Measurement of Polymers," Measurement Science \& Technology, V. 22, No. 12, 2011, doi: 10.1088/0957-0233/22/12/125703

13. Pittenger, B.; Erina, N.; and Su, C., "Quantitative Mechanical Property Mapping at the Nanoscale with PeakForce QNM," Application Note Veeco Instruments Inc, http://www.bruker-axs.com/uploads/AN128.pdf.

14. Vanlandingham, M. R.; McKnight, S. H.; Palmese, G. R.; Elings, J. R.; Huang, X.; Bogetti, T. A.; Eduljee, R. F.; and Gillespie Jr., J. W., "Nanoscale Indentation of Polymer Systems Using the Atomic Force Microscope," The Journal of Adhesion, V. 64, No. 1-4, 1997, pp. 31-59.

15. Sahin, O., and Erina, N., "High-Resolution and Large Dynamic Range Nanomechanical Mapping in Tapping-Mode Atomic Force Microscopy," Nanotechnology, V. 19, No. 44, 2008, doi: 10.1088/0957-4484/19/44/445717

16. Xiao, J. Z.; Li, W. G.; Corr, D. J.; and Shah, S. P., "Simulation Study on the Stress Distribution in Modeled Recycled Aggregate Concrete under Uniaxial Compression," Journal of Materials in Civil Engineering, ASCE, V. 25, No. 4, 2013, pp. 504-518.

17. Xiao, J. Z.; Li, W. G.; Corr, D. J.; and Shah, S. P., "Effects of Interfacial Transition Zones on the Stress-Strain Behavior of Modeled Recycled Aggregate Concrete," Cement and Concrete Research, V. 52, 2013, pp. 82-99.

18. Lee, J. W., and Duh, J. G., "Nanomechanical Properties Evaluation of Chromium Nitride Films by Nanoindentation and Nanowear Techniques," Surface and Coatings Technology, V. 188-189, 2004, pp. 655-661.

19. Oliver, W. C., and Pharr, G. M., "Improved Technique for Determining Hardness and Elastic Modulus Using Load and Displacement Sensing Indentation Experiments," Journal of Materials Research, V. 7, No. 6,1992 , pp. $1564-1583$.

20. Ulm, F. J.; Vandamme, M.; Bobko, C.; and Ortega, J. A., "Statistical Indentation Techniques for Hydrated Nanocomposites: Concrete, Bone, and Shale," Journal of the American Ceramic Society, V. 90, No. 9, 2007, pp. 2677-2692.

21. Xiao, J. Z.; Li, W. G.; Sun, Z. H.; Lange, D. A.; and Shah, S. P., "Properties of Interfacial Transition Zones in Recycled Aggregate Concrete Tested by Nanoindentation," Cement and Concrete Composites, V. 37, 2013, pp. 276-292.

22. Mondal, P.; Shah, S. P.; and Marks, L. P., "Nanomechanical Properties of Interfacial Transition Zone in Concrete," Nanotechnology in Construction 3: Proceedings of the NICOM3, 2009, pp. 315-320.

23. Wang, X. H.; Jacobsen, S.; He, J. Y.; Zhang, Z. L.; Lee, S. F.; and Lein, H. L., "Application of Nanoindentation Testing to Study the Interfacial Transition Zone in Steel Fiber Reinforced Mortar," Cement and Concrete Research, V. 39, No. 8, 2009, pp. 701-715.

24. Li, W. G.; Xiao, J. Z.; Sun, Z. H.; Kawashima, S.; and Shah, S. P., "Interfacial Transition Zones in Recycled Aggregate Concrete with Different Mixing Approaches," Construction \& Building Materials, V. 35, 2012, pp. 1045-1055.

25. Lee, K. M., and Park, J. H., "A Numerical Model for Elastic Modulus of Concrete Considering Interfacial Transition Zone," Cement and Concrete Research, V. 38, No. 3, 2008, pp. 396-402.

26. Rabe, U.; Janser, K.; and Arnold, W., "Vibrations of Free and Surface-Coupled Atomic Force Microscope Cantilevers: Theory and 
Experiment," The Review of Scientific Instruments, V. 67, No. 9, 1996, pp. 3281-3293.

27. Sahin, O.; Magonov, S.; Su, C.; Quate, C. F.; and Solgaard, O., "An Atomic Force Microscope Tip Designed to Measure Time-Varying Nanomechanical Forces," Nature Nanotechnology, V. 2, 2007, pp. 507-514.

28. Derjaguin, B. V.; Muller, V. M.; and Toporov, Y. P., "Effect of Contact Deformations on the Adhesion of Particles," Journal of Colloid and Interface Science, V. 53, No. 2, 1975, pp. 314-326.

29. Trtik, P.; Dual, J.; Muench, B.; and Holzer, L., "Limitation in Obtainable Surface Roughness of Hardened Cement Paste: Virtual Topographic Experiment Based on Focused Ion Beam Nanotomography Datasets," Journal of Microscopy, V. 6, No. 4, 2001, pp. 311-316.

30. Miller, M.; Bobko, C.; Vandamme, M.; and Ulm, F. J., "Surface Roughness Criteria for Cement Paste Nanoindentation," Cement and Concrete Research, V. 38, No. 4, 2008, pp. 467-476.

31. Jennings, H. M.; Thomas, J. J.; Gevrenov, J. S.; Constantinides, G.; and Ulm, F. J., "A Multi-Technique Investigation of the Nanoporosity of Cement Paste," Cement and Concrete Research, V. 37, No. 3, 2007, pp. 329-336.

32. Vandamme, M.; Ulm, F. J.; and Fonollosa, P., "Nanogranular Packing of C-S-H at Substochiometric Conditions," Cement and Concrete Research, V. 40, No. 1, 2010, pp. 14-26.

33. Alizadeh, R.; Beaudoin, J. J.; and Raki, L. R., "Mechanical Properties of Calcium Silicate Hydrates," Materials and Structures, V. 44, No. 1, 2011, pp. $13-28$

34. Kim, J. H.; Balogun, O.; and Shah, S. P., "Atomic Force Acoustic Microscopy to Measure Nanoscale Mechanical Properties of Cement
Pastes," Journal of the Transportation Research Board, V. 2141, 2010, pp. 102-108.

35. Masoero, E.; Del Gado, E.; Pellenq, R. J.-M.; Ulm, F. J.; and Yip, S., "Nanostructure and Nanomechanics of Cement: Polydisperse Colloidal Packing," Physical Review Letters, V. 109, No. 15, 2012, doi: 10.1103/ PhysRevLett.109.155503

36. Brehm, D., "Size Diversity in Cement Nanoparticles Optimizes Packing Density to Give Concrete Its Strength," Department of Civil and Environmental Engineering (CEE), Massachusetts Institute of Technology, Nov. 8, 2012, http://cee.mit.edu/news/releases/2012/ cement-particle-packing-density.

37. Pellenq, R. J. M.; Kushima, A.; Shahsavari, R.; Van Vliet, K. J.; Buehler, M. J.; Yip, S.; and Ulm, F. J., "A Realistic Molecular Model of Cement Hydrates," Proceedings of the National Academy of Sciences of the United States of America, V. 106, No. 38, 2009, pp. 16102-16107.

38. Allen, A. J.; Thomas, J. J.; and Jennings, H. M., "Composition and Density of Nanoscale Calcium-Silicate-Hydrate in Cement," Nature Materials, V. 6, 2007, pp. 311-316.

39. Fonseca, P. C.; Jennings, H. M.; and Andrade, J. E., “A Nanoscale Numerical Model of Calcium Silicate Hydrate," Mechanics of Materials, V. 43, No. 8, 2011, pp. 408-419.

40. DeJong, M. J., and Ulm, F.-J., "The Nanogranular Behavior of C-S-H at Elevated Temperatures (up to $700^{\circ} \mathrm{C}$ ), " Cement and Concrete Research, V. 37, No. 1, 2007, pp. 1-12.

41. Constantinides, G., and Ulm, F.-J., "The Nanogranular Nature of C-S-H," Journal of the Mechanics and Physics of Solids, V. 55, No. 1, 2007, pp. $64-90$ 